\title{
Involvement of GADD153 and cardiac ankyrin repeat protein in cardiac ischemia-reperfusion injury
}

\author{
Mi-Jin Lee ${ }^{1}$, Yong-Keun Kwak ${ }^{2}$, \\ Kyung-Ran You', Byung-Ho Lee ${ }^{3}$, \\ and Dae-Ghon Kim ${ }^{1,4}$ \\ ${ }^{1}$ Division of Hepatology and Gastroenterology \\ Department of Internal Medicine \\ ${ }^{2}$ Department of Pharmacology \\ The Research Institute of Clinical Medicine \\ Chonbuk National University Medical School and Hospital \\ Jeonju 561-712, Korea \\ ${ }^{3}$ Bio-Organic Science Division \\ Korea Research Institute of Chemical Technology \\ Daejeon 305-343, Korea \\ ${ }^{4}$ Corresponding author: Tel, 82-63-250-1681; \\ Fax, 82-63-254-1609; E-mail, daeghon@moak.chonbuk.ac.kr \\ DOI 10.3858/emm.2009.41.4.027
}

Accepted 26 November 2008

Abbreviations: CARP, cardiac ankyrin repeat protein; CAT, chloramphenicol acetyltransferase; DAPI, 4'-6'-diamidino-z-phenylindole; EMSA, electrophoretic mobility shift assay; ER, endoplasmic reticulum; GADD153, growth arrest and DNA damage-inducible gene 153; IR, ischemia reperfusion; ROS, reactive oxygen species; TTC, triphenyltetrazolium chloride

\begin{abstract}
Oxidative stress is critical for causing cardiac injuries during ischemia-reperfusion (IR), yet the molecular mechanism for this remains unclear. In the present study, we observe that hypoxia and reoxygenation, a component of ischemia, effectively induces apoptosis in the cardiac myocytes from neonatal rats and it concomitantly leads to induction of GADD153, an apoptosis-related gene. Furthermore, IR injury of rat heart showed a GADD153 overexpression in the ischemic area where the TUNEL reaction was positive. A downregulation of cardiac ankyrin repeat protein (CARP) was also observed in this ischemic area. Promoter deletion and reporter analysis revealed that hypoxia transcriptionally activates a GADD153 promoter through the AP-1 element in neonatal cardiomyocytes. Ectopic overexpression of GADD153 resulted in the downregulation of CARP expression. Accordingly, the induction of GADD153 mRNA were followed by the CARP down-regulation in an in vivo rat coronary ischemia/re-
\end{abstract}

perfusion injury model. These results suggest that GADD153 over-expression and the resulting downregulation of CARP may have causative roles in apoptotic cell death during cardiac IR injury.

Keywords: ANKRD1 protein, human; apoptosis; heart; reperfusion injury; transcription factor $\mathrm{CHOP}$

\section{Introduction}

The heart is occasionally exposed to ischemia during angina pectoris and myocardial infarction. These ischemic episodes cause cellular damage and cell loss, resulting in reduced cardiac function. Apoptosis of cardiac myocytes is known to be a cellular mechanism of the limited ischemic injury in the heart, while prolonged ischemia appears to primarily result in necrosis of the cardiac myocytes (Gottlieb et al., 1994; Kajstura et al., 1996, 1998). In addition, apoptosis in cardiac myocytes can be induced by hypoxia (Long et al., 1997), serum withdrawal (Sheng et al., 1997) or a combination of hypoxia and glucose and serum deprivation (Malhotra and Brosius, 1999). A better understanding of the mechanisms by which cardiomyocytes undergo apoptosis following oxidative stress would be helpful and this may also provide additional targets in the future for treating ischemic heart diseases. The expression of Fas antigen and the intracellular signaling pathways activated by p53 have been reported to be involved in the regulation of hypoxia-induced apoptosis of neonatal rat cardiomyocytes (Tanaka et al., 1994; Long et al., 1997). The JNK pathway or cyclin A/cdk2 activation plays an important role in signaling oxidative stress-induced apoptosis in cardiomyocytes (Turner et al., 1998; Adachi et al., 2001). The expression of the pro-apoptotic gene BNIP3 has recently been shown to contribute to apoptotic cell death (Guo et al., 2001). However, it is still not totally clear how hypoxia actually triggers cell death in cardiomyocytes.

The growth arrest/DNA damage-inducible gene 153 (GADD153) encodes GADD153 protein (also called CHOP-10), which belongs to the CCAAT/ enhancer protein (C/EBP) family of transcriptional factors (Cao et al., 1991) that regulate the cell cycle and apoptosis. GADD153 is transcriptionally activated and it is highly expressed following treat- 
ment of cells with a variety of growth arrest and/or DNA damaging factors (Fornace et al., 1988, 1989), such as calcium ionophores (Bartlett et al., 1992), glucose deprivation (Carlson et al., 1993), oxidative stress (Guyton et al., 1996), reductive stress (Halleck et al., 1997), endoplasmic reticulum stress (Wang et al., 1996) or activation of the acute phase response (Eastman et al., 1996). GADD153 has been implicated in the commitment to growth arrest or cell death. Microinjection of GADD153 induces $3 T 3$ cells to arrest at the $G_{1} / S$ boundary (Barone et al., 1994), while the ectopic expression of GADD153 causes M1 myeloblast leukemia cells to undergo apoptosis (Matsumoto et al., 1996). GADD153 was reported to sensitize cells to endoplasmic reticulum stress through mechanisms that involve the down-regulation of $\mathrm{Bcl}-2$ and enhanced oxidant injury (McCullough et al., 2001). Particularly, a hypoxia/oxidative stress-induced GADD153 gene expression was found in both pulmonary artery smooth muscle cells and vascular smooth cells (Chen et al., 2000; Tang et al., 2002). However, the studies to date have not explained whether GADD153 is over-expressed and the concomitant repression of CARP function during oxidative stress-induced apoptosis in cardiomyocytes in the rat heart. In this present study, we found that GADD153 was overexpressed by hypoxia or by ischemia/perfusion injury in cardiomyocytes, and that this overexpression as well as the resulting downregulation of CARP might be associated with apoptotic cell death in in vivo rat model. Therefore, we here address the molecular role of these proteins during hypoxia/IR injury-induced apoptosis in rat heart.

\section{Results}

\section{Induction of GADD153 and downregulation of CARP during hypoxia-induced apoptosis in the cardiomyocytes from neonatal rat}

The neonatal cardiac myocytes were cultured under hypoxia $\left(0.5 \% \mathrm{O}_{2}, 5 \% \mathrm{CO}_{2}\right.$, and $\left.94.5 \% \mathrm{~N}_{2}\right)$ for the time indicated and further incubated under normoxia for over $4 \mathrm{~h}$. Hypoxia/reoxygenation effectively induced apoptotic cell death in a time dependent manner in the cultured cariomyocytes from the neonatal rats. The apoptotic cells stained with the DNA-binding dye DAPI revealed condensed chromatin and fragmented nuclear morphologies that were characteristic of apoptosis. Overnight culture showed about $22.5 \%$ apoptosis at $24 \mathrm{~h}$ (Figure 1A). To support those findings, DNA fragmentation was analyzed by gel electrophoresis. The cells showed increased fragmentation of the lower molecular weight DNAs in a time dependent manner (data not shown). During the apoptotic cell death, we identified that the GADD153 was propor-

A

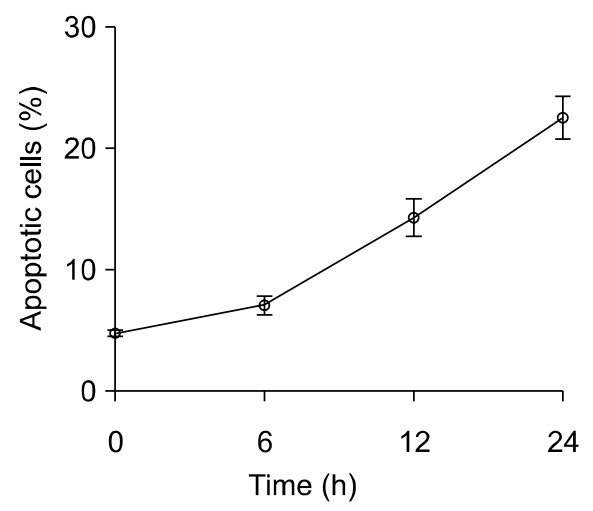

B
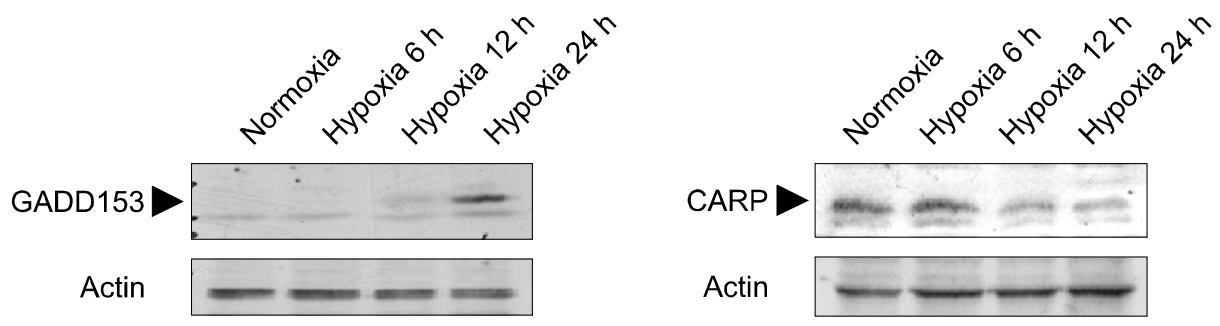

Figure 1. Hypoxia induced apoptosis in cardiac myocytes and the concomitant GADD153 expression and CARP downregulation. (A) Cariomyocytes from neonatal rat were cultured under hypoxic conditions and the apoptotic cells were counted by DAPI staining at the indicated time intervals. The values represent the mean \pm SE of three independent experiments that were done in duplicate. (B) Thirty micrograms of the extracted proteins were resolved by $12 \%$ SDS-PAGE and the proteins were transferred to the membrane. The blots were probed with polyclonal antibodies against GADD153 and CARP and the blots were then stripped and reprobed with a monoclonal antibody to actin as the loading control. The experiments were done at least thrice, and the result of one representative experiment is shown. 
tionally expressed, in a time dependent manner, according to hypoxia induced-apoptotic cell death of the rat neonatal cardiac myocytes. Concomitantly, CARP is downregulated by hypoxia in a time dependent manner (Figure 1B).

\section{Immunoreactivity for GADD153 or CARP in cardiac ischemia reperfusion injury}

We prepared a rat ischemia-reperfusion injury model. First, the size of infarct was assessed by Evans blue and TTC staining after $45 \mathrm{~min}$ of ischemia and $90 \mathrm{~min}$ of reperfusion. The viable myocardium was stained red and the infarcted myocardium appeared as pale yellow in the anterior wall of the left ventricle (Figure 2A, left). Accordingly, the myocardium was immunohistochemically stained with the antibody for GADD153 (Figure 2A, middle) or CARP (Figure 2A, right), respectively. The area adjacent to the TTC negative staining and the area of TTC negative staining grossly showed immunoreactivity for GADD153 and weaker immunoreactivity for CARP, respectively, than the TTC positive stained area.

\section{Effect of GADD153 overexpression on apoptosis}

To determine the role of GADD153 over-expression in the ischemic area, we carefully examined the GADD153 immunoreactivity of the cardiomyocytes in the ischemic area, as compared to that of the sham control (Figures 2B, left upper panels). IR injury evidently induced tissue disruption and longitudinal and transverse interfibrillar separation, as well as complete fiber disruption in some areas. Strong immunoreactivity against GADD153 was observed in the nuclei of the cardiomyocytes. Using the In Situ Cell Death Detection Kit, we also investigated the apoptotic cell death of the cardiomyocytes. The TUNNEL positive cells were clearly increased in the ischemic area (Figures 2B, left lower panels). For quantification of apoptotic cell death, 3 independent experiments (each $n=2$ or 3 ) were performed and consistent results were ob-

\section{A}
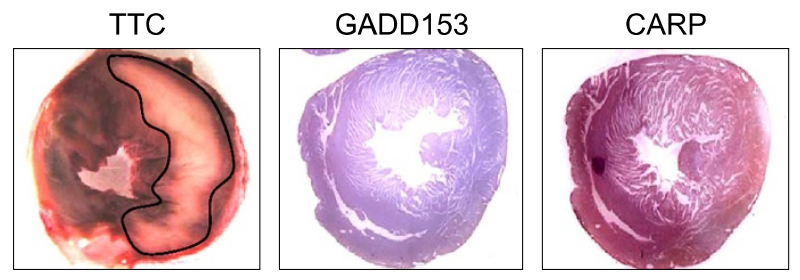

B

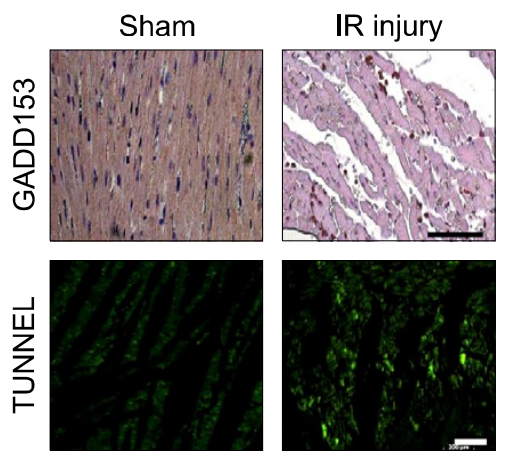

Apoptotic cardiac myocytes with TUNNEL positivit in the ischemia-reperfusion (IR) area

\begin{tabular}{ccc}
\hline Experiment & Sham & IR \\
\hline $1(n=3)$ & $1,3,11$ & $57,60,74$ \\
$2(n=3)$ & $2,0,2$ & $70,54,81$ \\
$3(n=2)$ & 1,1 & 75,82 \\
\hline Total $(n=8)$ & $1.4 \pm 0.3$ & $69.1 \pm 3.8^{*}$ \\
\hline
\end{tabular}

The number of TUNEL-positive nuclei is expresse as the number of apoptotic nuclei per 300 nuclei. Values are expressed as means \pm SEMs.

${ }^{*}, P<0.0001$; Student's $t$-test.

Figure 2. Induction of GADD153 and apoptosis by cardiac ischemia/ reperfusion injury in rats. (A) The myocardial sections were stained with TTC $24 \mathrm{~h}$ after acute occlusion of the left anterior descending (LAD) artery (left) $(n=8)$. The infracted area was not stained by TTC (circled area). Immunohistochemical staining against GADD153 was performed in the same level of the mycocardial section (middle) and immunohistochemical staining against CARP was also done (right). (B) Detection of apoptotic cardiomyocytes in association with the GADD153 expression. Immunohistochemical staining against GADD153 was performed in the myocardium of the sham controls and in the ischemic myocardium after 45 min ischemia following 90 min of reperfusion, respectively. Nuclear red staining indicates the GADD153-positive cells (left upper panels). TUNEL-positive cells were not detected or they were rarely detected in the myocardium of the sham controls (left lower panels). Apoptotic cardiac myocytes with TENEL-positivity in the ischemic area after 45 min ischemia following 90 min of reperfusion (right). Scale bar, $200 \mu \mathrm{m}$. 
tained (Figure 2B, right). IR injury significantly increased apoptotic cell death, as compared with the sham control.

\section{Role of AP-1 in hypoxic induction of GADD153}

The GADD153 promoter contains numerous regulatory elements that function in controlling the expression of this gene in response to cellular stresses (Park et al., 1992). Serial deletion of the GADD153 promoter was undertaken to highlight those regions that were responsive to hypoxic stimuli (Figure 3A). The maximal activation was observed by the promoter size from -306 to +14 , which contains the GADD153 AP-1 site (TGACTCA,
-244 to -238) as described previously (Guyton et al., 1996). To demonstrate the functional activity of the AP-1 in regulating GADD153 transcription, we used the AP-1-responsive reporter construct (TRE) $)_{4}$ TK-Luc, which displayed 5.2 fold enhanced activity $(P<0.01)$ in the transiently transfected cells under a hypoxic and reoxygenation condition, as compared to the normoxic condition (Figure 3B). Next, using a CAT assay the promoter activation in response to hypoxia was determined by the induction ratio relative to $A P-1$ mutant control (Figure $3 C$ ). The higher activation by 2.3-folds was observed by the AP1Gadd153-CAT construct, which contains the wild type GADD153 AP-1 site (TGACTCA, -244 to -238$)$ than the $\mathrm{AP}-1$ deletion mutant ( $\triangle \mathrm{AP} 1-$
A

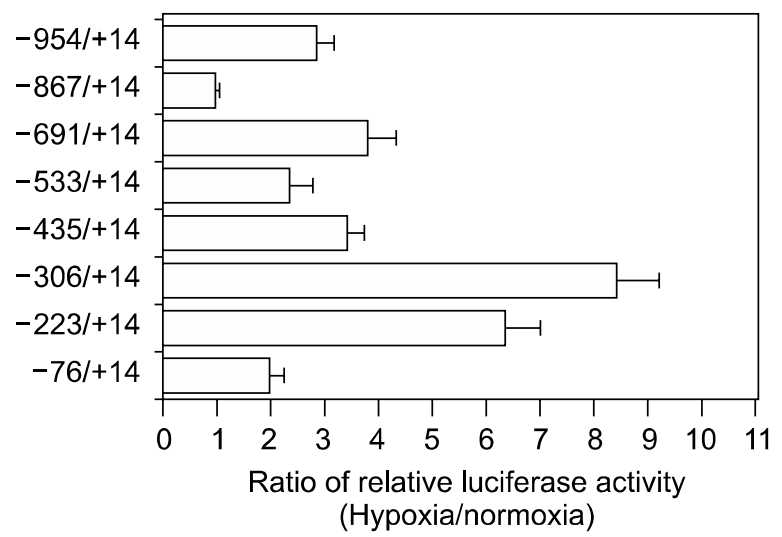

C

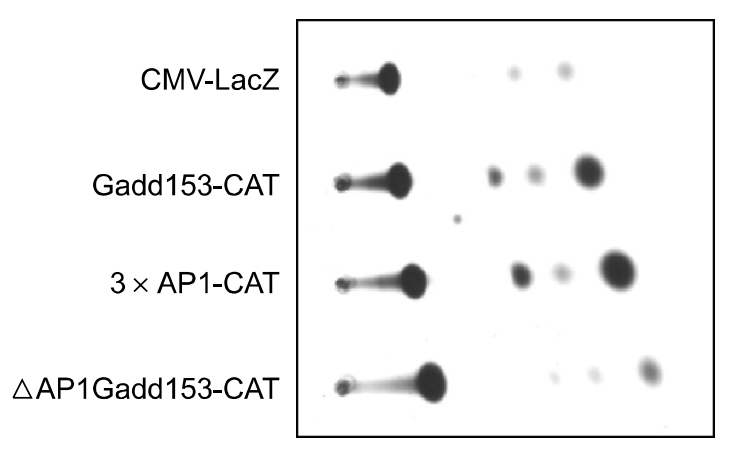

B
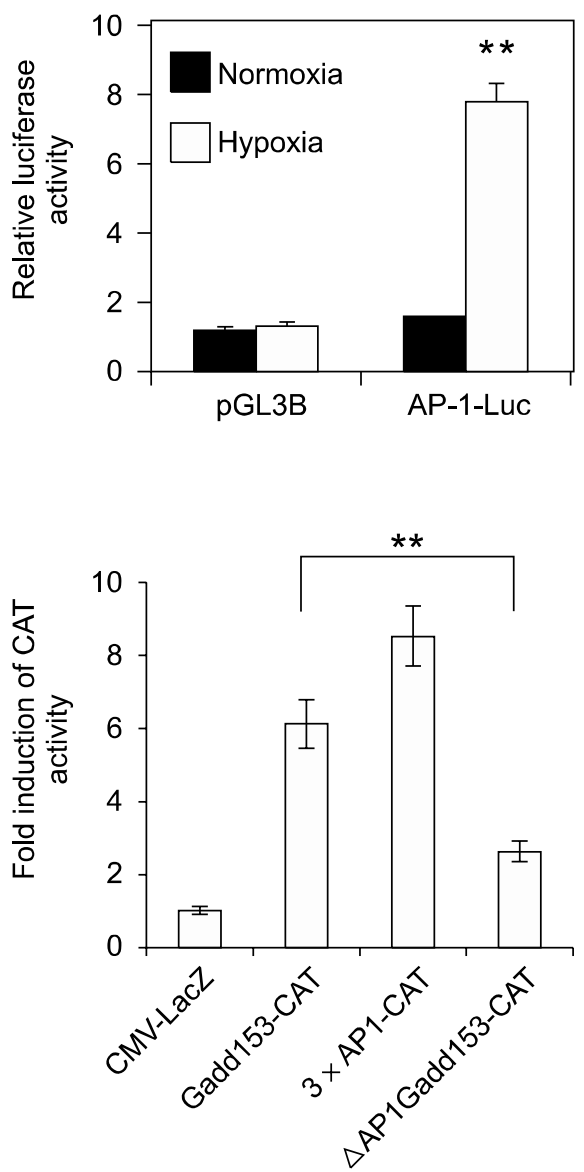

Figure 3. Mutation analysis of GADD153 promoter induction by hypoxia. (A) Induction of luciferase activity in the H9c2cells in response to hypoxia. The cells were transiently transfected with GADD153 promoter-deletion constructs and then the cells were harvested for determination of the luciferase activity $24 \mathrm{~h}$ after hypoxia/reoxygenation treatment. The induction ratios are expressed relative to the untreated controls. The values are means \pm SEs of three independent experiments. (B) Hypoxia-induced AP-1 activity. The cells were transfected with either the AP-1-responsive reporter construct (TRE) 4 -TK-Luc or the empty vector and then they were cultured under normoxic or hypoxic conditions. Each bar represents the mean \pm SE of two experiments performed in duplicate. (C) Hypoxia-induced CAT activity from GADD153 constructs containing wild type AP-1, deleted AP-1 mutant, or $3 \times$ AP-1 (left). The H9c2cells were transiently transfected with the indicated CAT reporter gene constructs and cultured under hypoxia and reoxygenation as described in the Methods. Activation is expressed relative to mock control. Each bar represents the mean \pm SE of two experiments performed in duplicate (right). $P<$ 0.01 . 
Gadd153-CAT) as described previously (Guyton et al., 1996). The maximal activation was observed by the $3 \times$ AP-1-CAT construct which contains a trimer of $A P-1$ consensus sequence linked to a minimal GADD153 promoter construct $(-36 /+21$ fragment). These results suggest that AP-1 is critical to oxidative regulation of GADD153 gene.

\section{Downregulation of CARP in the area of IR injury}

We next examined whether IR injury influences the CARP expression in the myocardium. The CARP expression was localized in the cytoplasm of cardiomyocytes (Figure 4A). The CARP expression was clearly decreased in the cardiomyocytes in the ischemic area, as compared with that of the sham operation. Furthermore, we closely investigated the CARP expression in the endocardium and subendocardial myocardium, which both receive their blood supply from intracardiac blood. Interestingly, the endocardium and subendocardial myocardium showed relatively normal levels of CARP expression in the papillary muscle of the left ventricle (Figure 4A, right), which demonstrated that IR injury by ligation of the coronary artery mainly occurred in the epicardium and epicardial side of the myocardium, but the endocardium and subendocardial myocardium were relatively spared.

\section{GADD153 expression leads to CARP downregulation in cardiomyocytes and in the area of IR injury}

We previously observed that oxidative stress results in GADD153 overexpression, which subsequently down-regulates the CARP transcript in the $\mathrm{H} 9 \mathrm{c} 2$ cells cultured under hypoxic conditions (Hahn et al., 2005). To examine this GADD153-mediated CARP repression in the neonatal cardiomyocytes cultured under normoxic conditions, we carried out the immunofluorescence assay. The results revealed that the expression of the endogenous CARP was localized in the cytoplasm of the cells, and that the ectopic overexpression of GADD153 was localized in the nuclei of cells, which in turn resulted in CARP's downregulation in the cytoplasm of the cardiomyocytes (Figure 4B). This suggests that GADD153 induction by IR injury might lead to the down-regulation of CARP. Next, we examined whether GADD153 induction regulated CARP transcript in the IR rat heart. GADD153 mRNA induction were more prominent in the area with $30 \mathrm{~min}$ ischemic injury than those in the area with non-

A

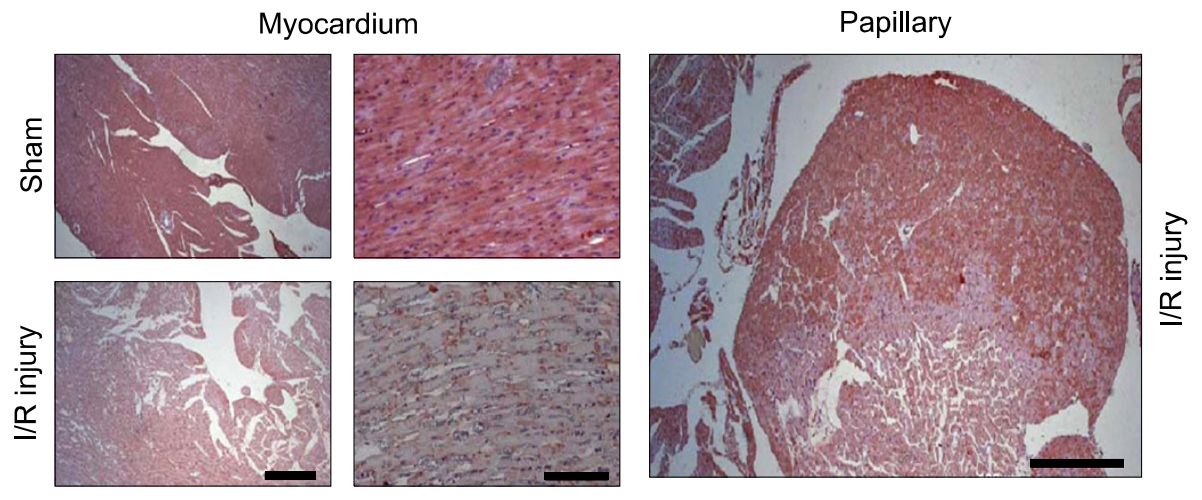

B
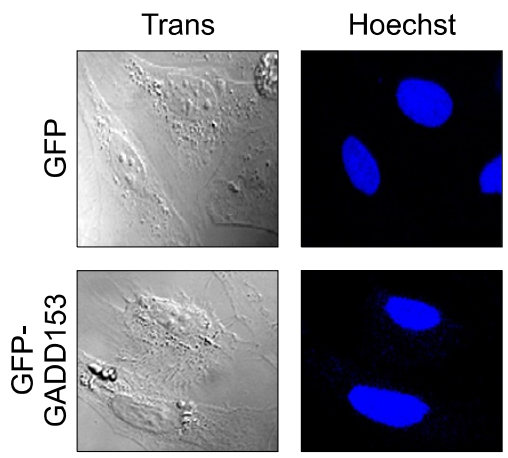

GFP
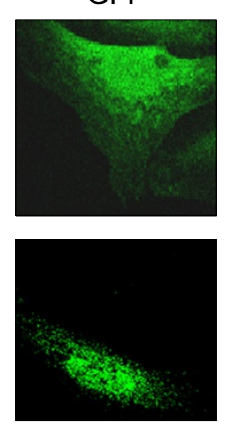

$\alpha$ CARP
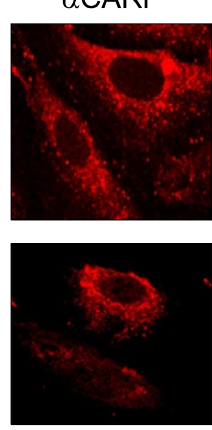
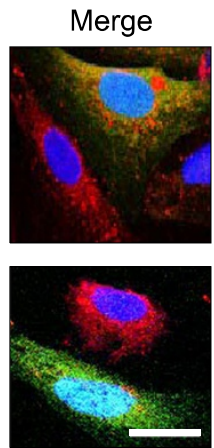

Figure 4. Downregulation of CARP by GADD 153 in the area of IR injury. (A) Photomicrographs of immunohistochemical staining for CARP in the cardiac tissues. Note the significant downregulation of CARP in the rat myocardium after ischemia and reperfusion compared with the sham control (left panels). The immunohistochemical staining for CARP on the endocardium and subendocardial myocardium of the papillary muscle was preserved after IR injury (right panel). Scale bar, $100 \mu \mathrm{m}$. (B) GADD153 down-regulates the CARP expression. The cardiomyocytes of neonatal rats were transfected with $2 \mu \mathrm{g}$ of the expression vectors for GFP-GADD153 or GFP. The cells were fixed with $4 \%$ paraformaldehyde and permeabilized in $0.4 \%$ Triton X-100 for 10 min at room temperature. The cells were stained for $15 \mathrm{~min}$ with $0.1 \mu \mathrm{g} / \mathrm{ml}$ Hoechst 33258 to visualize the nucleus (blue) and for indirect immunofluorescent staining against CARP (red). The cells were then stored in 50\% glycerol in PBS at $4^{\circ} \mathrm{C}$. The GFP fluorescence (green) was analyzed using confocal microscopy. Trans, transmission. Scale Bar, $20 \mu \mathrm{m}$. 
ischemic injury (Figure 5). But the downregulation of CARP mRNA was obvious in the area with 45 min ischemic injury, compared to the area with nonischemic injury. These results implicate that the GADD153 induction lead to the downregulation of CARP.

\section{Discussion}

Apoptosis can be influenced by a wide variety of regulatory stimuli. Experimental studies have shown that cardiomyocyte apoptosis is induced during hypoxia, continuous ischemia or ischemia followed by reperfusion (Gottlieb et al., 1994; Freude et al., 2000). The cellular mechanisms underlying both ischemia-reperfusion injury and apoptosis may involve cellular calcium overload, overproduction of oxygen-derived free radicals, cellular acidosis, inflammatory reaction and microcirculatory dysfunction (Entman et al., 1991; Thompson et al., 1995). This study examined the role of the proapoptotic transcriptional factor GADD153 in cardiac myocyte apoptosis in response to hypoxia during ischemia-reperfusion injury in a animal model. GADD153 is a transcriptional factor that is induced by cellular stress, and it has been suggested to play a role in the signal transduction from the stressed endoplasmic reticulum (ER) to apoptosis. In a previous study, hypoxic conditions clearly up-regulated GADD153 in rat cardiomyocytes. Therefore, the hypoxia-mediated apoptosis of cardiac myocytes appears to be related to ER stress. It has been recently shown that the over-expression of GADD153 sensitized cells to ER stress occurs through the down regulation of the $\mathrm{Bcl}-2$ expression. This down-regulation of the Bcl-2 expression increased the oxidant injuries, e.g. the depletion of cellular glutathione and the exaggerated production of ROS (reactive oxygen species) (Wang and Ron, 1996). Although only a few studies have addressed the mechanistic link between the GADD153 expression and cell death, GADD153 induction has been observed in the apoptotic pathways of $\beta$-adrenergic receptor stimulation in adult rat ventricular myocytes (Menon et al., 2007) and in stretch-induced vascular smooth muscle cell apoptosis (Cheng et al., 2007). In the present study, the GADD153 expression was positively correlated with apoptotic cell death of cardiac myocytes in the IR rat heart.

Furthermore, GADD153 over-expression and the concomitant downregulation of CARP were observed in the neonatal cardiomyocytes and in the IR rat heart. The CARP expression is increased during human heart failure (Zolk et al., 2002) and in a rat models of cardiac hypertrophy (Aihara et al., 2000), and it is decreased in the cardiomyocytes exposed to adriamycin (Jeyaseelan et al., 1997). CARP has been suggested to act as a nuclear transcription co-factor that negatively regulates the cardiac gene expression and it might play a key role in the pathophysiology of heart failure (Zolk et al., 2002). The $\beta$-adrenoceptor agonist isoprenaline induces hypertrophy and it increases the CARP expression (Zhu
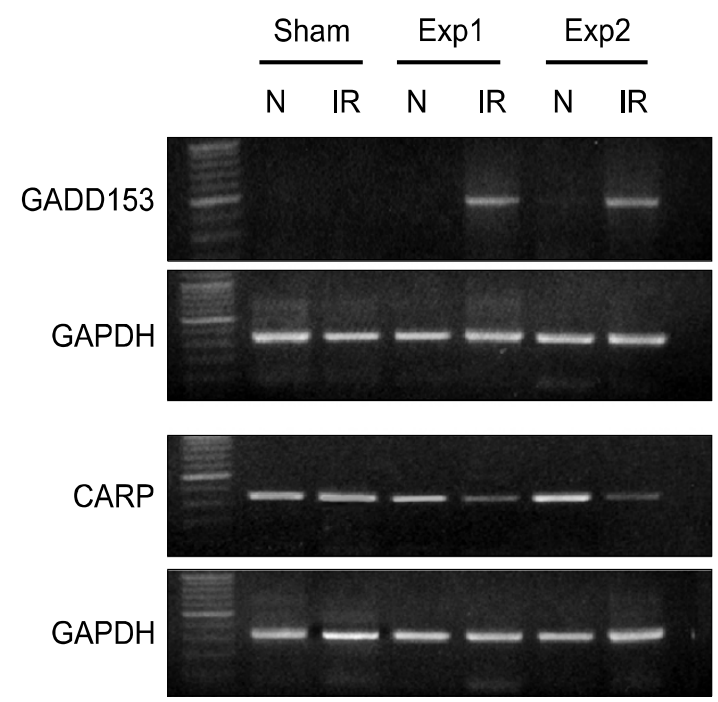

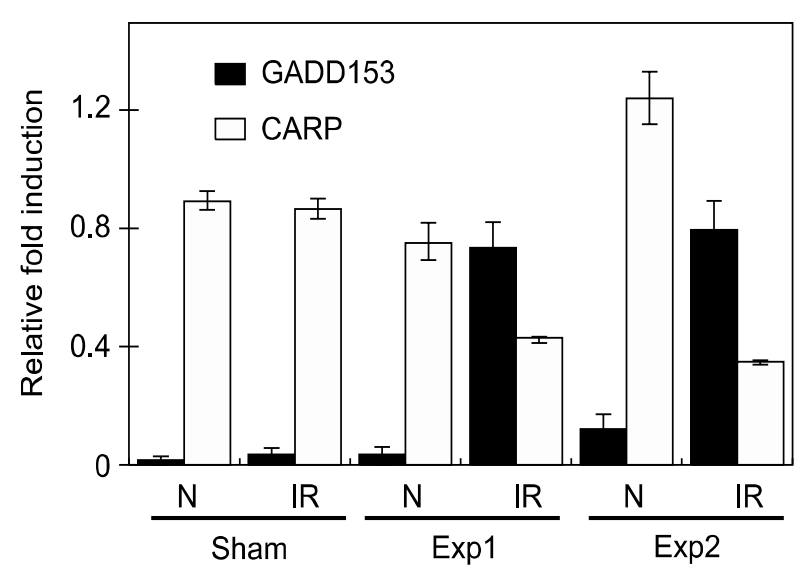

Figure 5. GADD153 induction was followed by transcriptional downregulation of CARP in the area of IR injury. Induction of GADD153 mRNA was detected by RT-PCR in the area with 30 min ischemic injury (IR), compared to the area with non-ischemic injury $(\mathrm{N})$ in the rat heart. Downregulation of CARP mRNA in the area with 45 min ischemic injury (IR), compared to the area with non-ischemic injruy (N) in the rat heart. Representatives of at least three independent experiments are shown. Relative fold induction after normalization to GAPDH mRNA (right panel). Values are means \pm SEM. Sham, sham operation; Exp, experiment. 
et al., 2003). Furthermore, CARP is up-regulated in response to shear stress in vitro (Yoshisue et al., 2002). These results suggest that the CARP expression might be associated with pathological stress in cardiomyocytes. Our previous study showed that hypoxic stress leads to the up-regulation of the GADD153 expression and the down-regulation of the CARP expression, and that the GADD153 expression is involved in the transcriptional downregulation of CARP (Han et al., 2005). Similarly, this study showed that GADD153 induction is inversely correlated with the CARP expression in the neonatal cariomyocytes and in the cardiomyocytes in the IR rat heart. Therefore, CARP downregulation may, at least in part, play a role in the GADD153-mediated sensitization of apoptotic cell death in the IR rat heart.

The hypoxia-regulated genes involved in controlling the cell cycle or apoptosis are either HIF-1 $\alpha$ dependent (those encoding the proteins p53, p21, $\mathrm{Bcl}-2)$ or HIF-1 $\alpha$-independent (p27, GADD153) (Carmeliet et al., 1998). In the present study, GADD153 over-expression was induced by IR injury in a rat model. GADD153 gene promoter activity is stimulated by the binding of the AP-1 family of proteins to an AP-1 site seen in a GADD153 gene promoter region (Guyton et al., 1996). In agreement with this result, we found that hypoxia stimulated the AP-1 promoter activity. The GADD153 gene promoter activity is stimulated, via oxidative stress, by the binding of the AP-1 family of proteins to an AP-1 site observed in a GADD153 gene promoter region.

In summary, this study demonstrated that IR-induced or hypoxia/reoxygenation-induced GADD153 induction is responsible for the in vitro and in vivo apoptotic cell death in cardiomyocytes. Hypoxic stress also down-regulates the CARP expression, which might be mediated by GADD153. Understanding the mechanisms whereby hypoxic stress damages the cardiac myocytes might help create novel therapeutic strategies that are aimed at reducing hypoxia or ischemia/reperfusion injury.

\section{Methods}

\section{Isolation and cultures of neonatal cardiomyocytes}

Primary cultures of cardiac myocytes were prepared from the ventricles of 1-2 day-old Sprague Dawley rats. The ventricles were separated from the atrial tissues and they were washed briefly in digestion solution $(116 \mathrm{mM} \mathrm{NaCl}$, $20 \mathrm{mM}$ HEPES, $1 \mathrm{mM} \mathrm{NaH}_{2} \mathrm{PO}_{4}, 5.5 \mathrm{mM}$ glucose, $5.4 \mathrm{mM}$ $\left.\mathrm{KCl}, 0.8 \mathrm{mM} \mathrm{MgSO}_{4}, \mathrm{pH} 7.4\right)$ that contained collagenase type II $(0.5 \mathrm{mg} / \mathrm{ml}$; Worthington Biochemical, Lakewood, $\mathrm{NJ})$ and pancreatin $(0.6 \mathrm{mg} / \mathrm{ml}$; Sigma Chemical, St Louis, $\mathrm{MO})$. The myocytes were dissociated in fresh digestion buffer for $20 \mathrm{~min}$ at $37^{\circ} \mathrm{C}$, collected by centrifugation and then they were resuspended in DMEM that was supplemented with $10 \%$ FBS, penicillin (100 units $/ \mathrm{ml}$ ) and streptomycin (100 mg/ml; Gibco Laboratories). The above steps were repeated six to eight times until the ventricles were completely digested. The isolated cells, which were a mixture of myocytes and nonmyocyte fibroblasts, were suspended in plating media (DMEM) and then plated onto 150-mm-diameter non-coated culture dishes for $1 \mathrm{~h}$ to reduce the number of contaminated cardiac fibroblasts. The myocytes were purified by using a Percoll gradient, replated in $1 \%$ collagen-precoated $100 \mathrm{~mm}$ culture dishes at a density of $4 \times 10^{6}$ cells in the same media with 0.1 $\mathrm{mM}$ bromodeoxyuridine (BrDU; Boehringer Mannheim, Indianapolis, IN), and then they were cultured at $37^{\circ} \mathrm{C}$ in a $\mathrm{CO}_{2}$ incubator. All the experiments were started $48 \mathrm{~h}$ after the initial plating; more than $98 \%$ of the cells at this time were myocytes, as determined by the cell morphology and myosin staining.

\section{Myocardiac ischemia-reperfusion model and immunohistochemical staining}

Male Sprague-Dawley rats (weighing 380-420 g each, Orient Co., Seoul, Korea) were anesthetized with sodium pentobarbital (60 mg/kg, i.p.), placed on a homeothermic blanket control unit at $37^{\circ} \mathrm{C}$ and then thoracotomized at the fifth intercostal space under artificial respiration $(60$ strokes $/ \mathrm{min}, 10 \mathrm{ml} / \mathrm{kg}$ ). Coronary artery occlusion was produced as previously described (Lee et al., 2001, 2004). After $30 \mathrm{~min}$ or $45 \mathrm{~min}$ of occlusion, the coronary artery was reperfused by removal of the polyethylene tube. After $90 \mathrm{~min}$ of reperfusion, the coronary artery was reoccluded and $2 \mathrm{ml}$ of $1 \%$ Evans blue was injected via a tail vein. The heart was removed and the left ventricle was dissected free from other structures; it was next sliced transversely into 1-mm thick sections. The image of the sections was captured by using a Hi-Scope (KH-2200 MD2, HiROX Co., Japan) to determine the area at risk. The sections were then incubated in $1 \%$ triphenyltetrazolium chloride for 15 $\min$ at $37^{\circ} \mathrm{C}$ and then they were fixed for $20-24 \mathrm{~h}$ in a $10 \%$ formalin solution to determine the infarct size, which corresponds to the area not stained by triphenyltetrazolium chloride (TTC). The images of the sections were captured again and analyzed with an image analyzing program (Image Pro Plus, Media Cybernetics, Silver Spring, MD). The arterial blood pressure was continuously monitored via an Isotec pressure transducer (Hugo Sachs Electronic) connected to a physiograph (WR 3300 Linearcorder, Graphtec, Tokyo, Japan). The electrocardiograms and heart rates were measured by Lead II using an electrocardiogram/rate coupler (Type 576; Hugo Sachs Electronic), and these were both analyzed by a computer program (PONEMAH physiology platform-model P3 Plus, Gould Inc., Cleveland, $\mathrm{OH}$ ). Immunohistochemical staining for GADD153 or CARP was then performed. The study's protocol was approved by the IRB on Laboratory Animal Care of Chonbuk National University, South Korea.

\section{In situ labeling of DNA fragments}

Using the In Situ Cell Death Detection Kit (Roche Applied 
Science, Indianapolis, IN), the TUNEL assay was performed to confirm apoptosis. The rat hearts were fixed with $4 \%$

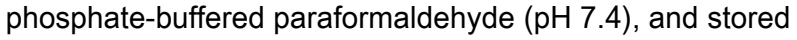
in $4 \%$ phosphate-buffered paraformaldehyde ( $\mathrm{pH} 7.4)$. After $24 \mathrm{~h}$, they were transferred into a $20 \%$ phosphatebuffered sucrose solution and cut into $10 \mu \mathrm{m}$ cryostat slices at the mid-ventricular level. The tissue sections were fixed with $4 \%$ phosphate-buffered paraformaldehyde $(\mathrm{pH}$ 7.4) for $30 \mathrm{~min}$ at room temperature and then they were incubated with a blocking solution $\left(3 \% \mathrm{H}_{2} \mathrm{O}_{2}\right.$ in water) for 5 min. This was followed with immersion in a permeabilization solution $(0.1 \%$ Triton $\mathrm{X}-100$ in $0.1 \%$ sodium citrate) for $2 \mathrm{~min}$ on ice. Each section was incubated for $1 \mathrm{~h}$ at $37^{\circ} \mathrm{C}$ with a TUNEL reaction mixture that contained TdT and FITC-labeled nucleotides and the manufacturer's instructions were followed. The FITC- TUNEL staining was visualized by fluorescence microscopy with using a Leica microscope (DMRBG, Leica).

\section{Promoter/reporter plasmids and transient transfection}

A genomic DNA fragment of the human GADD153 (p5W1) gene that contained the nt -954 +91 of 5'-flanking region was kindly provided by Dr. Nikki J. Holbrook (National Institute on Aging, Baltimore, MD) (Park et al., 1992). The genomic fragment of the p5W1 gene was subcloned into the Sma I and Hind III restriction sites of pGL3B (Promega, Madison, $\mathrm{WI}$ ). A series of 5'-nested deletion mutants was generated by exonucleae III digestion as described previously (Henikoff, 1984) and the sequences of the resulting constructs were verified by automated DNA sequencing. The $\mathrm{H} 9 \mathrm{c} 2$ cells were obtained from the American Tissue Culture Collection (ATCC, Rockville, MD) and these were transfected with the pGADD-LUC construct and using lipofectin (Gibco-BRL). The cells were plated at $2 \times 10^{4}$ cells per well in 24-well plates, and then $18 \mathrm{~h}$ later the cells were incubated at $37^{\circ} \mathrm{C}$ for $16 \mathrm{~h}$ with $500 \mathrm{ng}$ of the pGADD153-LUC plasmid and $50 \mathrm{ng}$ of the pRL-TK plasmid (Promega, Madison, WI), as well as lipofectin. Following the transfection, the cells were replenished with complete medium and they were treated with equitoxic levels of $4 \mathrm{HPR}$. The cells were lysed in $120 \mu \mathrm{l}$ lysis buffer at the indicated time intervals and then they were stored at $-20^{\circ} \mathrm{C}$ until assay was done. The luciferase activity was measured using the Dual-Luciferase Reporter Assay System (Promega) as per the manufacturer's instructions, and the luciferase activity was normalized by the Renilla luciferase activity. For determining the AP-1-mediated transcriptional regulation of $G A D D 153$, the cells were plated at $2 \times 10^{4}$ cells per well in 24-well plates, and then $18 \mathrm{~h}$ later the cells were incubated at $37^{\circ} \mathrm{C}$ for $16 \mathrm{~h}$ with $500 \mathrm{ng}$ of the AP-1-responsive reporter construct (TRE) $)_{4}$-TK-Luc (Lee et al., 1998 ) and $50 \mathrm{ng}$ of the pRL-TK plasmid (Promega), as well as with lipofectin.

\section{Western immunoblotting}

The cells were washed twice with cold PBS on ice and then harvested by scraping them off the plates with a rubber policeman. The cells were pelleted by centrifugation at $4^{\circ} \mathrm{C}$ and resuspended directly into Laemmli sample buffer that contained $62.5 \mathrm{mM}$ Tris $\mathrm{HCl}, \mathrm{pH} 6.8,2 \%$ SDS $(\mathrm{w} / \mathrm{v}), 10 \%$ glycerol $(\mathrm{w} / \mathrm{v})$ and $5 \%$ mercaptoethanol $(\mathrm{v} / \mathrm{v})$. The extracted proteins were resolved by $10 \%$ SDS-PAGE and transferred to nylon membranes as described previously (Wen et al., 200). The GADD153 polyclonal antibody (R-20) was purchased from Santa Cruz Biotechnology (Santa Cruz, CA). The rabbit polyclonal antibody for CARP (ANKRD1) was affinity purified from the sera of immunized rabbits as described previously (Park et al., 2005).

\section{Chloramphenicol acetyltransferase (CAT) assays}

The H9c2 cells $\left(10^{6}\right)$ were transfected by the lipofectin method with 1 pmol of plasmid reporter DNAs including -778/+21 Gadd153-CAT, -778/+21 $\triangle$ AP1Gadd153-CAT, or $3 \times$ AP1-CAT (Guyton et al., 1996). Cell extracts of H9c2 cells were analyzed for CAT activity by the method described previously (You et al., 2003). Reaction mixtures containing $30 \mu \mathrm{g}$ cell extract, $0.2 \mu \mathrm{Ci}\left[{ }^{14} \mathrm{C}\right]$ chloramphenicol and $4.4 \mathrm{mM}$ acetyl coenzyme $\mathrm{A}$, were incubated at $37^{\circ} \mathrm{C}$ for $3 \mathrm{~h}$. The reaction products were separated on thin layer plates, and the percent of chloramphenicol substrate acetylates was determined by liquid scintillation counting. The $\beta$-galactosidase expression (pCMV- $\beta$-gal) vectors were used as negative controls.

\section{RT-PCR}

The mRNA was reverse transcribed with using oligo $d(T) 15$ primers (Boehringer Mannheim) to prepare the singlestranded cDNA, and this was followed by PCR amplification of the GADD153 mRNA or the CARP mRNA. Amplification was performed for 35 cycles for GAPDH as an internal control in a thermal cycler (Perkin Elmer). Each cycle consisted of $1 \mathrm{~min}$ of denaturation at $94^{\circ} \mathrm{C}, 1 \mathrm{~min}$ of annealing at $67^{\circ} \mathrm{C}$ and $1 \mathrm{~min}$ of extension at $72^{\circ} \mathrm{C}$. The sequences of primers used were as follows, GADD153 (forward: 5'-GCTCTAGAGGGCTGCAGAGATGGC-3', reverse: 5'-GGAATTCGGGGACTGATGCTCCCA-3') and GAPDH (forward: 5'ATCACCATCTTCCAGGAGCG-3', reverse: 5'-GATGGCATGGACTGTGGTCA-3'). CARP RT-PCR amplification was done for 35 cycles. The sequences of the CARP primers are forward 5'-GCTTGAATCCACAGCCATCC-3' and reverse 5-'TGCCAGTGTAGCACCAGATC-3'. The PCR conditions consisted of $1 \mathrm{~min}$ of denaturation at $94^{\circ} \mathrm{C}, 1 \mathrm{~min}$ of annealing at $57^{\circ} \mathrm{C}$ and $1 \mathrm{~min}$ of extension at $72^{\circ} \mathrm{C}$. The PCR products were analyzed by electrophoresis on $1.2 \%$ agarose gels.

\section{Statistical analysis}

All the data was entered into Microsoft Excel 5.0, and GraphPad Software was used to perform the two-tailed $t$ tests. All $P$ values less than 0.05 were considered to be statistically significant.

\section{Acknowledgments}

This work was supported by the National R\&D Program for Cancer Control from the Ministry of Health, Welfare and Family affairs (0620220-1) and the 21C Frontier Functional 
Human Genome Project from the Ministry of Science and Technology (FG08-12-03), Republic of Korea. We thank Dr. Nikki J. Holbrook and Dr. Joel F. Habener for providing plasmids.

\section{References}

Adachi S, Ito H, Tamamori-Adachi M, Ono Y, Nozato T, Abe $\mathrm{S}$, Ikeda Ma, Marumo F, Hiroe M. Cyclin A/cdk2 activation is involved in hypoxia-induced apoptosis in cardiomyocytes. Circ Res 2001;88:408-14

Aihara Y, Kurabayashi M, Saito Y, Ohyama Y, Tanaka T, Takeda S, Tomaru K, Sekiguchi K, Arai M, Nakamura T, Nagai $R$. Cardiac ankyrin repeat protein is a novel marker of cardiac hypertrophy: role of M-CAT element within the promoter. Hypertension 2000;36:48-53

Barone MV, Crozat A, Tabaee A, Philipson L, Ron D. CHOP (GADD153) and its oncogenic variant, TLS-CHOP, have opposing effects on the induction of $\mathrm{G} 1 / \mathrm{S}$ arrest. Genes Dev 1994;8:453-64

Bartlett JD, Luethy JD, Carlson SG, Sollott SJ, Holbrook NJ. Calcium ionophore A23187 induces expression of the growth arrest and DNA damage inducible CCAAT/enhancerbinding protein (C/EBP)-related gene, gadd153. Ca2+ increases transcriptional activity and mRNA stability. J Biol Chem 1992;267:20465-70

Cao Z, Umek RM, McKnight SL. Regulated expression of three C/EBP isoforms during adipose conversion of 3T3-L1 cells. Genes Dev 1991;5:1538-52

Carlson SG, Fawcett TW, Bartlett JD, Bernier M, Holbrook NJ. Regulation of the C/EBP-related gene gadd153 by glucose deprivation. Mol Cell Biol 1993;13:4736-44

Carmeliet P, Dor Y, Herbert JM, Fukumura D, Brusselmans $K$, Dewerchin M, Neeman M, Bono F, Abramovitch R, Maxwell P, Koch CJ, Ratcliffe P, Moons L, Jain RK, Collen D, Keshert E. Role of HIF-1alpha in hypoxia-mediated apoptosis, cell proliferation and tumour angiogenesis. Nature 1998;394:485-90

Chen R, Harrod KS, Olson JW, Gillespie MN. Regulation of gadd153 mRNA expression by hypoxia in pulmonary artery smooth muscle cells. Res Commun Mol Pathol Pharmacol 2000;108:3-14

Cheng WP, Hung HF, Wang BW, Shyu KG. The molecular regulation of GADD153 in apoptosis of cultured vascular smooth muscle cells by cyclic mechanical stretch. Cardiovasc Res 2008;77:551-9

Eastman HB, Fawcett TW, Udelsman R, Holbrook NJ. Effects of perturbations of the hypothalamic-pituitaryadrenal axis on the acute phase response: altered C/EBP and acute phase response gene expression in lipopolysaccharide- treated rats. Shock 1996;6:286-92

Entman ML, Michael L, Rossen RD, Dreyer WJ, Anderson DC, Taylor AA, Smith CW. Inflammation in the course of early myocardial ischemia. FASEB J 1991;5:2529-37

Fornace AJ Jr, Alamo I Jr, Hollander MC. DNA damageinducible transcripts in mammalian cells. Proc Natl Acad Sci

\section{U S A $1988 ; 85: 8800-4$}

Fornace AJ Jr, Nebert DW, Hollander MC, Luethy JD, Papathanasiou M, Fargnoli J, Holbrook NJ. Mammalian genes coordinately regulated by growth arrest signals and DNA-damaging agents. Mol Cell Biol 1989;9:4196-203

Freude B, Masters TN, Robicsek F, Fokin A, Kostin S, Zimmermann R, Ullmann C, Lorenz-Meyer S, Schaper J. Apoptosis is initiated by myocardial ischemia and executed during reperfusion. J Mol Cell Cardiol 2000;32:197-208

Gottlieb RA, Burleson KO, Kloner RA, Babior BM, Engler RL. Reperfusion injury induces apoptosis in rabbit cardiomyocytes. J Clin Invest 1994;94:1621-8

Guo K, Searfoss G, Krolikowski D, Pagnoni M, Franks C, Clark K, Yu KT, Jaye M, Ivashchenko Y. Hypoxia induces the expression of the pro-apoptotic gene BNIP3. Cell Death Differ 2001;8:367-76

Guyton KZ, Xu Q, Holbrook NJ. Induction of the mammalian stress response gene GADD153 by oxidative stress: role of AP-1 element. Biochem J 1996;314:547-54

Halleck MM, Holbrook NJ, Skinner J, Liu H, Stevens JL. The molecular response to reductive stress in LLC-PK1 renal epithelial cells: coordinate transcriptional regulation of gadd 153 and grp78 genes by thiols. Cell Stress Chaperones 1997;2:31-40

Han XJ, Chae JK, Lee MJ, You KR, Lee BH, Kim DG. Involvement of GADD153 and cardiac ankyrin repeat protein in hypoxia-induced apoptosis of $\mathrm{H} 9 \mathrm{c} 2$ cells. J Biol Chem 2005;280:23122-9

Henikoff S. Unidirectional digestion with exonuclease III creates targeted breakpoints for DNA sequencing. Gene 1984;28:351-9

Jeyaseelan R, Poizat C, Baker RK, Abdishoo S, Isterabadi LB, Lyons GE, Kedes L. A novel cardiac-restricted target for doxorubicin. CARP, a nuclear modulator of gene expression in cardiac progenitor cells and cardiomyocytes. J Biol Chem 1997;272:22800-8

Kajstura J, Cheng W, Reiss K, Clark WA, Sonnenblick EH, Krajewski S, Reed JC, Olivetti G, Anversa P. Apoptotic and necrotic myocyte cell deaths are independent contributing variables of infarct size in rats. Lab Invest 1996;74:86-107

Kajstura J, Liu Y, Baldini A, Li B, Olivetti G, Leri A, Anversa $P$. Coronary artery constriction in rats: necrotic and apoptotic myocyte death. Am J Cardiol 1998;82:30K-41K

Lee BH, Seo HW, Yoo SE, Kim SO, Lim H, Shin HS. Differential action of KR-31378, a novel potassium channel activator, on cardioprotective and hemodynamic effects. Drug Dev Res 2001;54:182-90

Lee $\mathrm{BH}$, Seo HW, Yoo SE. Cardioprotective effects of (2S,3R,4S)- $N$ '-benzyl- $N$ '-cyano- $N$-(3,4-dihydro-2-dimeth oxymethyl-3-hydroxy-2-methyl-6-nitro-2H-benzopyran-4yl)-guanidine (KR-31372) in rats and dogs. Pharmacology 2004;70:74-82

Lee SK, Kim HJ, Na SY, Kim TS, Choi HS, Im SY, Lee JW. Steroid receptor coactivator-1 coactivates activating protein1-mediated transactivations through interaction with the c-Jun and c-Fos subunits. J Biol Chem 1998;273:16651-4 
Long X, Boluyt MO, Hipolito ML, Lundberg MS, Zheng JS, O'Neill L, Cirielli C, Lakatta EG, Crow MT. p53 and the hypoxia-induced apoptosis of cultured neonatal rat cardiac myocytes. J Clin Invest 1997;99:2635-43

Malhotra R, Brosius FC 3rd. Glucose uptake and glycolysis reduce hypoxia-induced apoptosis in cultured neonatal rat cardiac myocytes. J Biol Chem 1999;274:12567-75

Matsumoto M, Minami M, Takeda K, Sakao Y, Akira S. Ectopic expression of CHOP (GADD153) induces apoptosis in M1 myeloblastic leukemia cells. FEBS Lett 1996;395:143-7

McCullough KD, Martindale JL, Klotz LO, Aw TY, Holbrook NJ. Gadd153 sensitizes cells to endoplasmic reticulum stress by down-regulating $\mathrm{Bcl} 2$ and perturbing the cellular redox state. Mol Cell Biol 2001;21:1249-59

Menon B, Johnson JN, Ross RS, Singh M, Singh K. Glycogen synthase kinase-3beta plays a pro-apoptotic role in betaadrenergic receptor-stimulated apoptosis in adult rat ventricular myocytes: Role of beta1 integrins. J Mol Cell Cardiol 2007;42:653-61

Park JH, Liu L, Kim IH, Kim JH, You KR, Kim DG. Identification of the genes involved in enhanced fenretinide-induced apoptosis by parthenolide in human hepatoma cells. Cancer Res 2005;65:2804-14

Park JS, Luethy JD, Wang MG, Fargnoli J, Fornace AJ Jr, McBride OW, Holbrook NJ. Isolation, characterization and chromosomal localization of the human GADD153 gene. Gene 1992;116:259-67

Sheng Z, Knowlton K, Chen J, Hoshijima M, Brown JH, Chien KR. Cardiotrophin 1 (CT-1) inhibition of cardiac myocyte apoptosis via a mitogen-activated protein kinase-dependent pathway. Divergence from downstream CT-1 signals for myocardial cell hypertrophy. J Biol Chem 1997;272:5783-91

Tanaka M, Ito H, Adachi S, Akimoto H, Nishikawa T, Kasajima T, Marumo F, Hiroe M. Hypoxia induces apoptosis with enhanced expression of Fas antigen messenger RNA in cultured neonatal rat cardiomyocytes. Circ Res 1994;75: 426-33

Tang JR, Nakamura M, Okura T, Takata Y, Watanabe S, Yang ZH, Liu J, Kitami Y, Hiwada K. Mechanism of oxidative stress-induced GADD153 gene expression in vascular smooth muscle cells. Biochem Biophys Res Commun 2002;290:1255-9

Thompson CB. Apoptosis in the pathogenesis and treatment of disease. Science 1995;267:1456-62

Turner NA, Xia F, Azhar G, Zhang X, Liu L, Wei JY. Oxidative stress induces DNA fragmentation and caspase activation via the c-Jun $\mathrm{NH} 2$-terminal kinase pathway in $\mathrm{H} 9 \mathrm{c} 2$ cardiac muscle cells. J Mol Cell Cardiol 1998;30:1789-801

Wang XZ, Lawson B, Brewer JW, Zinszner H, Sanjay A, Mi LJ, Boorstein R, Kreibich G, Hendershot LM, Ron D. Signals from the stressed endoplasmic reticulum induce C/EBPhomologous protein (CHOP/GADD153). Mol Cell Biol 1996;16:4273-80

Wang XZ, Ron D. Stress-induced phosphorylation and activation of the transcription factor CHOP (GADD153) by p38 MAP Kinase. Science 1996;272:1347-9

Wen J, You KR, Lee SY, Song CH, Kim DG. Oxidative stressmediated apoptosis. The anticancer effect of the sesquiterpene lactone parthenolide. J Biol Chem 2002;277: 38954-64

Yoshisue H, Suzuki K, Kawabata A, Ohya T, Zhao H, Sakurada K, Taba Y, Sasaguri T, Sakai N, Yamashita S, Matsuzawa Y, Nojima H. Large scale isolation of non-uniform shear stress-responsive genes from cultured human endothelial cells through the preparation of a subtracted cDNA library. Atherosclerosis 2002;162:323-34

You KR, Liu MJ, Han XJ, Lee ZW, Kim DG. Transcriptional regulation of the human transferrin gene by GADD153 in hepatoma cells. Hepatology 2003;38:745-55

Zhu WZ, Wang SQ, Chakir K, Yang D, Zhang T, Brown JH, Devic E, Kobilka BK, Cheng H, Xiao RP. Linkage of beta1-adrenergic stimulation to apoptotic heart cell death through protein kinase A-independent activation of $\mathrm{Ca} 2+1$ calmodulin kinase II. J Clin Invest 2003;111:617-25

Zolk O, Frohme M, Maurer A, Kluxen FW, Hentsch B, Zubakov D, Hoheisel JD, Zucker IH, Pepe S, Eschenhagen T. Cardiac ankyrin repeat protein, a negative regulator of cardiac gene expression, is augmented in human heart failure. Biochem Biophys Res Commun 2002;293:1377-82 